\title{
Empowering schools for waste free safe hydration during climate change: water for schools: a practical model.
}

\author{
Elizabeth Beaumont* \\ Founder of water for schools, highly commended leadership for sustainability, Australia
}

Accepted on December 05, 2017

School Children in Australia face a very hot future. Temperatures are increasing and so does the incidents of hospital admissions and increased heat stress deaths.

"There is strong empirical evidence indicating that climate change poses significant immediate and long term risks to the health of Australians." Deaths associated with heat stress are now higher than deaths associated with natural disasters (Figure 1).

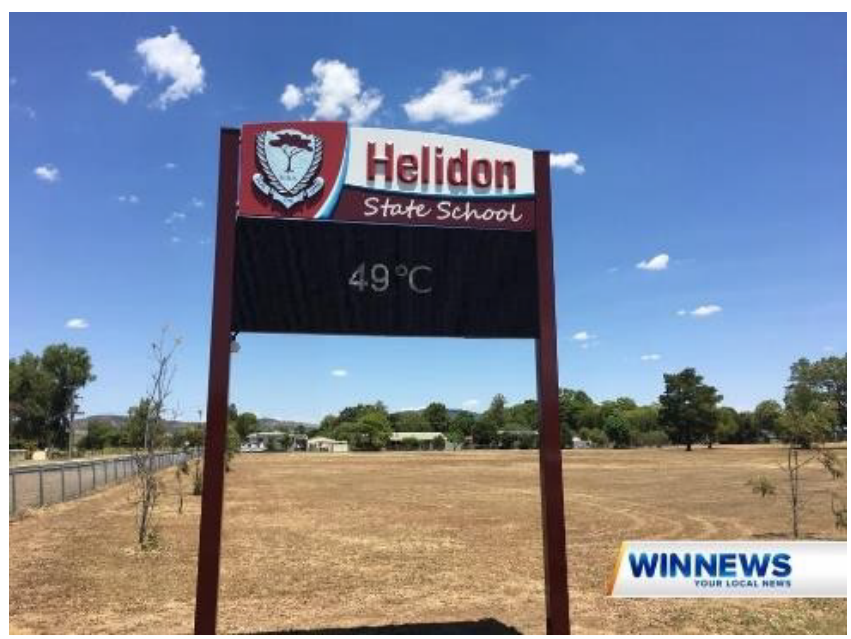

Figure 1. School in Australia.

Source: p17," Towards a national strategy on climate health and wellbeing for Australia discussion paper."

The current paradigm with children attending schools in Australia is they have access to bubblers. Extreme climatic events pose challenges to each municipality and some schools are responsible for harvesting their own water. Hygiene issues will continue to escalate with up facing spigots prone to microbial growth and exposure to heat. Bottled water is for sale in most schools at an unregulated price and housed in Polyethylene terephthalate (PET) and purchased through the school canteen. This limits the dynamic physiological needs arising in children particularly in heat wave conditions (Figure 2) [1-4].

Water for Schools proposes to introduce a small annual affordable levy to ensure that all school children have access to safe chilled, filtered water via the installation of a system that UV purifies and safe guards water against water borne diseases, example, hepatitis, salmonella, and E coli.

"Climate change is likely to affect several other important causes of gastroenteritis in similar ways as Salmonella. "p. 24 Bambridge et al 2008. To alleviate this risk, Water for Schools proposes the installation of a water filtration system that connects to the existing water supply of the school.

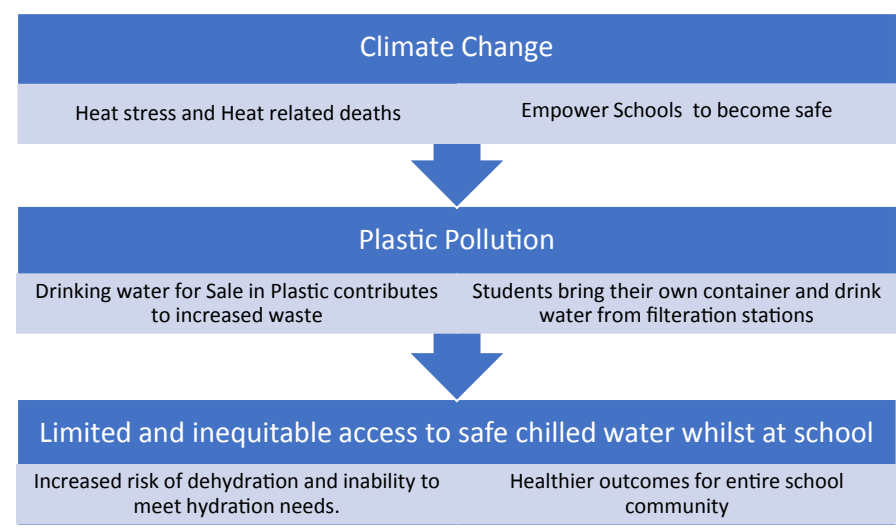

Figure 2. Identifying the problems and potential solutions.

This increases the power of everyone to meet their dynamic needs for water.

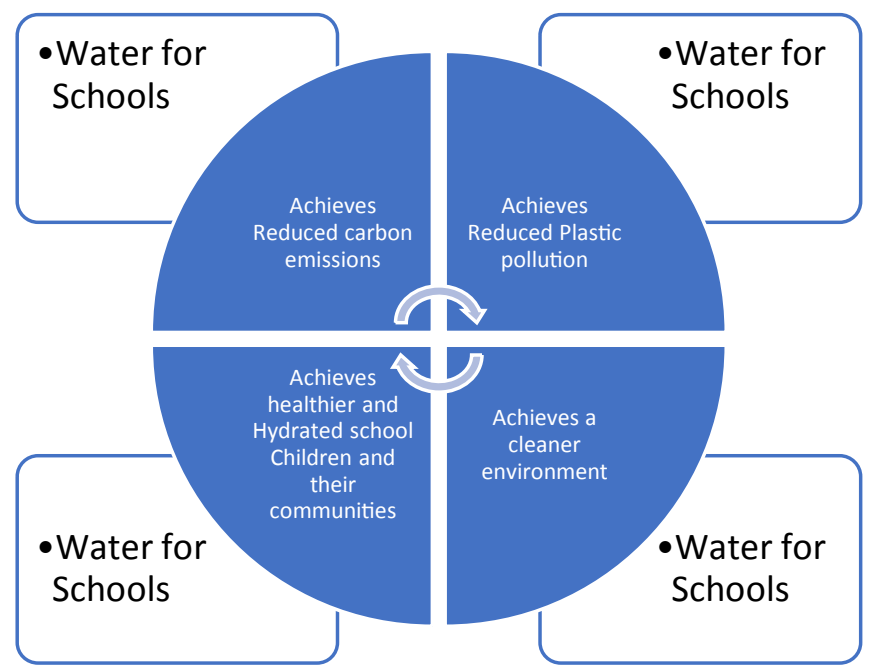

Water for Schools works collaboratively with key stake holders and returns a portion of the levy back to Parents and Citizens associations to offset the loss of income. Water for Schools is consistent with Australian Federal Government policy.

- Drink plenty of fluids during hot weather - cool water is best Credit : http://conditions.health.qld.gov.au

Water for Schools is a transferrable model and operates as a legal entity.

Elizabeth Beaumont is the Founder of Water for Schools $\subset$, a retired transplant nurse and wildlife advocate. In 2015 she received a High Commendation from the Premier of Queensland for successfully campaigning an academic institution to ban 
Citation: Beaumont E. Empowering Schools for Waste Free Safe Hydration during Climate Change: Water for Schools: A Practical Model. Environ Risk Assess Remediat. 2017;2(1):9-10

the sale of water housed in polyethylene terephthalate. To date more than 80,000 bottles have been removed from circulation in favour of filtered water refill stations. Elizabeth has endorsed a children's Book regarding the marine pollution. She actively volunteers for Surfrider Foundation, Clean Up Australia Day and has appeared on radio within her community and internationally to raise awareness about plastic pollution.

\section{References}

1. https://www.climatecouncil.org.au/silentkillerreport
2. http://www.abc.net.au/news/2016-01-25/heat-stressdeaths-rise-following-australia-day/7113030

3. https://d3n8a8pro7vhmx.cloudfront.net/caha/pages/40/ attachments/original/1476390215/CAHA_Discussion_ Paper_v04.pdf

4. http://www.garnautreview.org.au/CA25734E0016A131/ WebObj/03-AThreehealthoutcomes/\$File/03-A\%20 Three\%20health\%20outcomes.pdf

\section{*Correspondence to:}

Elizabeth Beaumont

Founder of Water for Schools

Highly Commended Leadership for Sustainability Australia

Tel: 0407649095

E-mail: elizabethb77@outlook.com 